
jornalismo ambiental. Anuario Electrónico de Estudios en Comunicación Social "Disertaciones", 10(2), 120-

132. Doi: http://dx.doi.org/10.12804/revistas.urosario.edu.co/disertaciones/a.4790

\title{
DENGUE, ZIKA E CHIKUNGUNYA: ANÁLISE DA COBERTURA DO RISCO DE DOENÇAS ASSOCIADAS ÀS MUDANÇAS CLIMÁTICAS SOB A ÓTICA DO JORNALISMO AMBIENTAL
}

\section{Dengue, Zika and Chikungunya: An Analysis of the Risk Coverage of Diseases Associated with Climate Change from the Perspective of Environmental Journalism}

Dengue, zika y chikungunya: un análisis de la cobertura del riesgo de enfermedades asociadas al cambio climático desde la perspectiva del periodismo ambiental

Cláudia Herte de Moraes, Universidade Federal de Santa María (Brasil) chmoraes@gmail.com

Eloisa Beling Loose, Centro Universitário Internacional (Brasil)

eloisa.loose@gmail.com

Ilza Maria Tourinho Girardi, Universidade Federal do Rio Grande do Sul (Brasil) ilza.girardi@ufrgs.br 


\section{RESUMO}

Entendemos que o Jornalismo Ambiental pode ser visto como parte da comunicação de riscos associada ao meio ambiente, pois muitos conflitos derivados da relação homem-natureza se transformam em percepção de perigos ou ameaças à vida. A fim de refletir sobre seu papel no contexto dos riscos, analisamos a cobertura do jornal Folha de São Paulo a respeito de três doenças (Dengue, Zika e Chikungunya), que podem ser relacionadas à intensificação das mudanças climáticas. Com a orientação teórico-metodológica da análise do discurso, concluímos que a abordagem está baseada nas fontes científicas, estrangeiras e com formações discursivas que apontam as perspectivas do otimismo tecnológico, da incerteza científica e da precaução.

Palavras-chave: riscos, mudanças climáticas, Aedes aegypti, jornalismo ambiental, análise do discurso.

\section{ABSTRACT}

We understand that the Environmental Journalism can be seen as part of the Risk Communication associated with the environment, since many conflicts derived from man-nature relationship become perceived danger or threat to life. In order to reflect on their role in the context of the risks, we analyze the coverage of Folha de S. Paulo about three diseases (dengue, chikungunya and zika), which can be related to the intensification of climate change. With the theoretical and methodological orientation of Discourse Analysis, we conclude that the approach is based on scientific sources, foreign and Discursive formations that link the prospects of technological optimism, scientific uncertainty and caution.

Keywords: Risks, climate changes, Aedes aegypti, environmental journalism, discourse analysis.

\section{RESUMEN}

Entendemos que el periodismo ambiental puede ser visto como parte de la comunicación del riesgo asociada con el ambiente, debido a que muchos conflictos derivados de la relación hombre-naturaleza son percibidos como peligrosos o una amenaza para la vida. Con el fin de reflexionar sobre su rol en los contextos de crisis, analizamos la cobertura del Folha de S. Paulo sobre tres enfermedades (dengue, chikungunya y zika), que pueden relacionarse con la intensificación del cambio climático. Con la orientación teórica y metodológica del análisis del discurso, concluimos que el abordaje está basado en fuentes científicas, extranjeras y con informaciones discursivas que apuntan al optimismo tecnológico, la incertidumbre científica y la precaución.

Palabras clave: riesgo, cambio climático, Aedes aegypti, periodismo ambiental, análisis del discurso. 


\section{Contexto de risco das epidemias no Brasil}

No Brasil, nos últimos meses, o mosquito Aedes aegypti, transmissor de doenças como dengue, zika e chikungunya, tem assumido grande visibilidade através dos meios de comunicação. Em 2015, segundo dados do Ministério da Saúde, foram registradas 1,6 milhão de notificações de dengue, sendo esta considerada uma das piores epidemias do país (desde o início da série histórica, em 1990, este foi o maior número de casos registrados). Se não bastasse isso, o aumento de casos de zika e febre chikungunya também aumentaram, trazendo grande preocupação tanto para as autoridades, quanto para a população. Em 2016, foram registrados 495.266 casos prováveis de dengue no país no período de 3 de janeiro a 5 de março. Foram notificados 13.676 casos prováveis de febre de chikungunya, sendo que 550 foram confirmados. Em relação à febre pelo vírus zika, foram confirmados três óbitos no território nacional, todos no mesmo período (Brasil, 2016). Nesse sentido, se faz fundamental a comunicação correta e eficiente dos riscos relacionados à proliferação do vetor transmissor, o mosquito já citado, e as formas de evitar as doenças. E o jornalismo, como espaço legitimado de credibilidade e de ampla visibilidade pode contribuir, por meio de uma cobertura contextualizada, na prevenção e minimização de tais riscos.

Considerando as especificidades da comunicação de riscos e suas intersecções com o Jornalismo Ambiental, o objetivo deste trabalho é analisar como a mudança do clima é tratada na cobertura dos riscos associados às doenças transmitidas pelo Aedes aegypti, já que muitos estudos demonstram forte correlação entre o aumento de mosquitos e as alterações climáticas. Para tanto, fizemos uma pesquisa por palavras-chave na versão impressa do jornal Folha de São Paulo, um dos principais do Brasil' ${ }^{1}$, no período $1^{\circ}$ de janeiro de 2015 a 15 de fevereiro de 2016, de modo a verificar como as causas, consequências e ações de enfrentamento estão sendo divulgadas pela imprensa dita de referência. Sublinhamos que há a compreensão de que tais riscos, embora impliquem diretamente na saúde das pessoas, possuam ligação com aspectos mais amplos, de ordem ambiental. Logo, o debate que propomos visa articular os resultados da pesquisa com os preceitos da comunicação de risco e do Jornalismo Ambiental, duas áreas de estudo relativamente novas no contexto brasileiro.

Também assinalamos que a coleta de dados abrangeu o período que inicia em janeiro de 2015, justamente por ser esse o ano da realização da Conferência das Partes, que trata das mudanças climáticas, a COP-21, realizada em dezembro na cidade de Paris. Tal fato poderia ter sensibilizado jornalistas a prestarem mais atenção nas possíveis implicações entre as doenças e o aumento de temperatura média global.

\section{Aedes aegypti e questões ambientais: breves conexões}

Para além de ser uma questão de saúde pública, a proliferação do mosquito Aedes aegypti está atrelada a uma série de questões de ordem ambiental, muitas delas associadas às mudanças do clima. Mendonça (2005) alerta que não se deve creditar toda a incidência de doenças tropicais ao clima, mas, ao mesmo tempo, não se deve menosprezar sua influência. Há outros fatores que devem ser considerados, como as especificidades de cada

1 Segundo a Associação Nacional de Jornais (ANJ), em 2015 a Folha de São Paulo foi o terceiro maior jornal impresso do Brasil, com uma média de circulação paga de 175.441, e o primeiro em média de circulação digital, com 134.895. As informações estão disponíveis em: http://www.anj.org.br/maiores-jornais-do-brasil/. 
lugar. Entretanto, o pesquisador pontua que a dengue "[...] tem apresentado elevação no número de casos bem como ampliação de sua área de ocorrência, o que pode estar ligado ao processo de intensificação do aquecimento estufa planetário" (Mendonça, 2005, p.108). Este pesquisador relata que há estudos que demonstram a ampliação da doença para a Região Sul, que apresenta tendências à intensificação do aquecimento, "[...] o que evidência uma clara relação entre sua expansão e a intensificação do efeito-estudo global na escala regional” (p.111).

Barcellos et al. (2009) lembram que as alterações climáticas, além de trazer alguns problemas, podem solucionar outros, como a diminuição da alta mortalidade devido às temperaturas rigorosas do inverno. Estes autores apresentam as consequências das mudanças do clima (que podem ser diretas a partir de desastres como enchentes, ondas de calor, secas e queimadas, ou indiretas a partir da escassez de alimento e proliferações de vetores, por exemplo), mas destacam que

[...] o clima e os eventos extremos não podem ser responsabilizados pelos agravos à saúde. Pesaram sobre os efeitos a incapacidade do setor saúde de lidar com situações de emergência e as profundas desigualdades sociais, mesmo em países centrais com grande tradição de políticas de bem-estar social (Ibid., $\mathrm{s} / \mathrm{p})$.

Dessa forma, mais importante que associar o aumento de doenças à intensificação das alterações do clima (que conforme o Painel Intergovernamental de Mudanças Climáticas, IPCC, na sigla em inglês, têm origem predominante nas atividades antropogênicas), é reconhecer que a vulnerabilidade das pessoas frente a estas é decorrente de uma combinação de fatores derivados da degradação ambiental, fruto do sistema social no qual estamos inseridos, somado ao crescimento populacional.

As condições sociais como situação de moradia, alimentação e acesso aos serviços de saúde são fatores que aumentam a vulnerabilidade de populações expostas aos episódios das mudanças climáticas, que somados à exposição a poluentes atmosféricos, poderá apresentar efeitos sinérgicos com agravamento de quadros clínicos. Em áreas sem ou com limitada infraestrutura urbana, principalmente em países em desenvolvimento, todos esses fatores podem recair sobre as populações mais vulneráveis, aumentando a demanda e gastos de serviços de saúde (Barcellos et al., 2009, s/p).

Frente a isso, é preciso considerar não apenas o aquecimento do planeta, mas questões mais amplas de ordem socioambiental. Seja o desmatamento de florestas, que extermina o habitat natural de inúmeras espécies, podendo levar à extinção de seus predadores e favorecer um crescimento descontrolado de outras, resultando em desequilíbrio ambiental; seja o aumento progressivo de impermeabilização do solo, que fomenta o fenômeno de ilhas de calor, existem elementos que agravam a vulnerabilidade para enfrentamento das mudanças do clima. Há uma complexidade em volta desse processo.

O que queremos chamar atenção é para o fato de que, apesar de todos estarem suscetíveis aos riscos climáticos, as afetações serão diferentes, seja porque seus efeitos são diferentes, seja porque existirão vulnerabilidades de diversas formas. No Brasil, muitas questões climáticas ainda precisam ser melhor investigadas, porém há dados que mostram que a América Latina, em razão da maior dependência dos recursos naturais e das profundas desigualdades sociais, será bastante impactada pelos efeitos da mudança do clima (PNUD, 2007). Quanto ao Aedes aegypty, foco desta análise, há uma relação também com o descuido dos próprios cidadãos em acabar com os criadouros do mosquito. Uma 
pesquisa realizada pela Secretaria da Saúde do Paraná2 revelou que 45\%, dentre os 19 mil focos de larvas do mosquito encontrados no estado, estão em depósitos de lixo em casas e empresas. É preciso que informações a respeito de prevenção e educação ambiental sejam divulgadas, de modo que todos possam estar conscientes dos riscos decorrentes do desleixo. Afinal, segundo Barcellos et al. (2009, s/p), "a dengue é considerada a principal doença reemergente nos países tropicais e subtropicais".

\section{O jornalismo no âmbito da Comunicação de Risco}

O jornalismo pode ser visto como uma, dentre outras, forma de comunicar os riscos. A comunicação de riscos (risk communication, em inglês) abrange um processo mais amplo e interdisciplinar, que vai além de disseminar informações a respeito dos riscos (não somente aqueles de natureza ambiental). Geralmente, está intrinsecamente relacionada ao próprio gerenciamento do risco, que envolve desde atores possivelmente causadores do risco até aqueles que foram direta ou indiretamente afetados por este.

A comunicação de riscos independe dos meios de comunicação, muito embora faça seu uso a fim de amplificar o alcance das informações, seja para informar sobre quais medidas está tomando para minimizar o risco, seja para convocar os cidadãos a fazerem sua parte. De acordo com Powell e Leiss (2005, p.192), ela representa “[...] o processo de troca entre a comunidade acadêmica, os profissionais das agências reguladoras, os grupos de interesse e o público em geral, em que se considera como melhor avaliar e gerenciar os riscos".

A proposta da comunicação de risco surge a partir do momento em que se percebe que a exposição objetiva do que é um risco ou não por parte dos especialistas, baseada em estimativas, nem sempre resulta no entendimento ou na percepção do risco por parte da população. Como a construção do que é risco ou não depende de experiências, contextos e outros fatores individuais e grupais, a percepção dos leigos não costuma corresponder àquela dos peritos. Há riscos que geram muita preocupação nas pessoas, embora causem poucos danos, enquanto outros que matam muitos não são percebidos com o mesmo estado de alerta. Com isso, a comunicação de risco pode gerar tranquilidade em casos nos quais os riscos não são tão preocupantes e também pode impor urgência em outros riscos que são vistos com apatia pelo público. A comunicação de risco, desde o começo, sempre foi centrada em um objetivo mais prático: melhorar o diálogo entre os diferentes sujeitos e obter um grau de consenso social que permita um eficaz gerenciamento dos riscos.

Desse modo, seja na gestão de catástrofes, riscos ou mesmo da prevenção dos mesmos, a necessidade que os públicos percebam os fatores causadores e as maneiras de superá-los é de suma relevância e depende da mediação dos comunicadores. Como a avaliação dos riscos é intrínseca à percepção dos riscos e a comunicação dos riscos colabora de diferentes formas para a formatação deste processo, podemos dizer que as escolhas tomadas para gerir e enfrentar os riscos também dependem, parcialmente, das soluções que nos são apresentadas. Além disso, Serra (2009) enfatiza três funções da comunicação de riscos, todas aplicáveis ao jornalismo sobre riscos: 1) agendamento e enquadramento, pois a imprensa nos diz sobre o que pensar e também como pensar;

2 Disponível em http://www.gazetadopovo.com.br/vida-e-cidadania/meio-ambiente/lixo-e-reduto-de-larvas-do-aedes-aegypti-eapta2hf6lup0aqw8awcmi5ou 
2) intermediação, pois estabelece ligações entre os poderes instituídos e os cidadãos; e 3) legitimação da tomada de decisões, ao apresentar-se como fórum de discussão e espaço de análise das questões abordadas.

\section{Jornalismo Ambiental e a cobertura de riscos}

Entendemos o Jornalismo Ambiental a partir da complexidade ambiental e do saber ambiental, que questiona a racionalidade econômica como instrumento de dominação da natureza. Assim, o saber ambiental pode ser compreendido como um saber sobre as formas de apropriação do mundo, através das relações de poder que estão presentes também nas formas dominantes de conhecimento, ou seja, dos paradigmas da racionalidade econômica (Leff, 2009). O Jornalismo Ambiental:

Busca a inclusão da perspectiva holística e sua conexão inequívoca com o todo, produzindo notícias mais contextualizadas e menos fragmentadas. Desta forma, o jornalismo ambiental parte de uma nova concepção teórico-prática centrada no agir e no pensar o jornalismo, a partir da ótica da sustentabilidade do planeta, buscando a ampliação do número de fontes da área a serem consultadas, o aprofundamento do conteúdo e a abordagem qualificada das notícias de meio ambiente (Girardi et al, 2013, p.74).

O conceito de Jornalismo Ambiental inclui um posicionamento crítico, questionador, plural, que traz à luz questões que são complexas e que são deixadas de lado na abordagem do mundo. Consideramos, a partir disso, uma contribuição importante na cobertura dos riscos climáticos, quando estão presentes os preceitos do Jornalismo Ambiental, praticado a partir da valorização da cultura e do meio ambiente, quanto da economia e da política, ou seja, com abordagens que tenham "maior aprofundamento contextual e a oferta de diferentes visões de mundo, sendo, portanto, essencial à pluralidade de fontes” (Moraes, 2015, p.70).

Associando-se às questões discutidas por Serra (2009) sobre a mediatização dos riscos, trazemos a visão do Jornalismo Ambiental no tratamento de agendamento e enquadramento. Sob esta ótica, os riscos ambientais e climáticos devem ser tratados de forma complexa, trazendo ao público mais sobre o contexto e as interconexões. A sociedade, para enfrentar os riscos ambientais presentes na crise global, necessita que o enquadramento não seja monolítico ou monocausal, características das notícias ambientais, como aponta Hannigan (1995). Se o jornalismo nos diz sobre quais temas pensar e como pensá-los, não podemos abrir mão de que estes sejam abordados de forma mais ampla, o que propicia um entendimento maior sobre os caminhos possíveis para o enfrentamento dos riscos climáticos.

O segundo ponto, considerado fundamental para Serra (2009), destaca o papel da intermediação social operada pelo jornalismo. No entanto, sabemos que os poderes instituídos geralmente têm acesso rotineiro aos meios de comunicação, sendo fontes "habituais", conforme Molotch e Lester (1974, apud Traquina, 2005), transformando-se, portanto, uma parte privilegiada na mediação do que "deveria ser" um diálogo. A proposta do Jornalismo Ambiental indica que este deve ser praticado trazendo uma variedade de fontes que possam dar conta dos diferentes interesses em jogo, em especial, dos cidadãos que não tem acesso ao poder. Como dizem Kovach e Rosenstiel (2004), o jornalismo deve dar voz aos cidadãos, para que eles possam ser ouvidos pelos governos, para que façam parte do debate público.

Quanto ao terceiro ponto, mais abrangente e complexo, consideramos importante pontuar que o estabelecimento de um fórum de discussão somente é possível caso os dois aspectos anteriores estejam sendo considerados 
pelo jornalismo. Desta forma, podemos dizer que as tomadas de decisões feitas a partir da ideia de formação de consensos sociais podem estar seriamente ameaçadas, caso não exista contextualização das informações, ou que sejam visibilizadas apenas as opiniões dos setores majoritários do poder econômico, político, científico ou social.

São estes os pressupostos que trataremos de verificar em nossa análise: de um lado, a premência da comunicação de riscos e da ampliação do debate sobre o risco climático em relação à proliferação de doenças; de outro, o compromisso do jornalismo com o momento de busca de soluções para a adaptação às mudanças do clima, que inclui novas formas de entender o risco, bem como novas formas de conviver em sociedade.

\section{Análise da cobertura da Folha de São Paulo}

Utilizamos o aporte teórico-metodológico da análise de discurso (AD) de linha francesa, especialmente a partir de Pêcheux. A AD constitui-se uma forma de interpretação em que são valorizados vários fatores em relação à construção dos discursos, entre eles as condições de produção e os efeitos de sentido do discurso. Para Pêcheux (1990), ao analista importa deixar entender que a análise está presente já quando se recorta um objeto e dele se faz a descrição.

Um conceito que é fundamental na AD é de Formação Discursiva (FD), na medida em que esta é entendida como o domínio do saber, que representa um modo de se relacionar com a ideologia vigente (Indusrky, 1998), pois se considera que uma FD determina aquilo que pode ser dito em determinada conjuntura histórica, afetada pela ideologia, sendo também excludente daquilo que não pode ser dito, de seus silêncios.

Os efeitos de sentido são encontrados por marcas que são trazidas pelo texto, quer seja pela paráfrase, entendida como um retorno e um reforço a outros discursos já ditos (interdiscursos), quanto à polissemia, que aponta para sentidos que tendem para fora do sentido principal do discurso.

Para observação do material jornalístico, optamos por descartar do corpus todos os materiais opinativos, ou seja, artigos, colunas de opinião e opinião/manifestação do leitor. Desta forma, observamos o jornalismo a partir da construção discursiva das notícias, como um gênero narrativo diferenciado e espaço considerado especial, tanto pelas empresas, quanto por jornalistas e leitores, por tratar diretamente de fatos de interesse público.

A coleta foi realizada pelo mecanismo de busca do próprio site da empresa jornalística, utilizando combinações de expressões, conforme mostrado no Quadro 1. As combinações foram decorrentes de nosso objetivo de pesquisa, sendo ele analisar de que forma a mudança do clima poderia ser trazida pelo discurso jornalístico, a partir da cobertura das doenças dengue, chikungunya e zika.

Quadro 1 - Resultado das buscas pelas expressões de interesse da pesquisa

\begin{tabular}{|l|l|}
\hline \multicolumn{1}{|c|}{ Expressões pesquisadas } & \multicolumn{1}{c|}{ Retorno em número de textos } \\
\hline Dengue + mudança climática; dengue + aquecimento global & Dois textos (uma entrevista e uma reportagem) \\
\hline Mudança climática + aedes aegypti; aquecimento global + aedes aegypti & Nenhum resultado \\
\hline Zika + mudança climática; zika + aquecimento global & Um resultado (uma entrevista) \\
\hline Chikungunya + mudança climática; chikungunya + aquecimento global & Nenhum resultado \\
\hline
\end{tabular}

Fonte: Elaboração própria. 
Numa primeira avaliação, podemos dizer que quanto mais específico o tema, o número de matérias se reduz. Obviamente, as matérias de mudança climática se mostram muito generalistas e, quando temos problemas específicos, como as epidemias de dengue, de chikungunya e de zika, a mudança do clima não é citada. No entanto, destacamos que o método da $A D$ não prescinde da quantidade do material coletado, mas da análise qualitativa realizada.

Passamos a apresentar a análise e a discussão dos três textos encontrados para visualizar de que forma o tema foi tratado e refletir sobre suas lacunas, traçando um paralelo com as bases teóricas discutidas anteriormente. Apesar dos dados epidemiológicos demonstrarem riscos em relação à febre chikungunya, a pesquisa retornou dados apenas quando relacionamos os termos "dengue" ou "zika". Consideramos este fato importante para destacar o quanto o jornalismo ainda é feito a partir de problemas já instalados na sociedade, e pouco atua de forma preventiva em relação à prováveis riscos e questões emergentes.

Os textos foram publicados nas editorias "Saúde + Ciência"; "Cotidiano"; e "Saúde”. A partir desta localização editorial, o jornal indica aos leitores que há uma interface entre os temas da ciência em relação ao mosquito, bem como afetações diretas na saúde da população e nas ações do seu dia a dia. Os tipos de texto revelam que apenas uma reportagem foi elaborada pelo jornal. Desta forma, inferimos que o tema não foi suficientemente trabalhado no sentido de trazer contraditórios e contextualizações mais amplas. As entrevistas pingue-pongue são espaços jornalísticos que se prestam mais a trazer novidades e apresentar um ponto de vista privilegiado e relevante, mas apenas de um pesquisador o que, embora seja importante no cenário da construção dos temas para o público, acaba por não trazer aprofundamento baseado em contrapontos de outras fontes ou setores.

Como o conjunto de textos é relativamente pequeno, consideramos que o tema teve pouquíssima entrada no jornal analisado. Esta perspectiva revela um não-agendamento da questão, mesmo diante do contexto do avanço das doenças no país e, como já discutido, do desenho do risco climático figurar claramente no horizonte. Voltando-nos, no entanto, ao que foi publicado, indicamos que as fontes foram todas trazidas do campo científico, de pesquisadores de tecnologia ou saúde, não havendo, novamente, espaço para contraponto. Mas o que mais chama a atenção é que são pesquisadores estrangeiros, fontes comuns em material de ciência e tecnologia. O jornal não buscou pesquisadores brasileiros, prováveis fontes para as matérias. Isso demonstra uma escolha discursiva importante que pode apontar para o sentido da ausência, de que não haveria pesquisadores sobre o tema no Brasil. Certamente há pesquisadores brasileiros que poderiam ser ouvidos pelo jornal, tanto que existem centros de excelência e pesquisadores renomados que pesquisam as doenças e vírus em questão, e o tema da mudança do clima. 
Quadro 2 - Matérias analisadas

\begin{tabular}{|c|c|c|c|c|c|}
\hline Data & Título & Editoria/Texto & Fontes & Sentido geral & $\begin{array}{l}\text { Formação } \\
\text { Discursiva }\end{array}$ \\
\hline 16.05 .15 & $\begin{array}{l}\text { Plataforma online } \\
\text { poderá ajudar a } \\
\text { prever epidemias }\end{array}$ & $\begin{array}{l}\text { Saúde } \\
\text { Entrevista }\end{array}$ & $\begin{array}{l}\text { Rebecca Moore - engenheira } \\
\text { Google }\end{array}$ & $\begin{array}{c}\text { Tecnologia ajuda a } \\
\text { mapear florestas } \\
\text { Pode pressionar } \\
\text { governos }\end{array}$ & $\begin{array}{l}\text { Otimismo } \\
\text { tecnológico }\end{array}$ \\
\hline 15.08 .15 & $\begin{array}{c}\text { Relação entre mais } \\
\text { calor e doenças não } \\
\text { é clara }\end{array}$ & $\begin{array}{l}\text { Ciência+ Saúde } \\
\text { Reportagem }\end{array}$ & $\begin{array}{c}\text { Cientistas } \\
\text { Patrick L. Kinney, Universidade } \\
\text { Columbia. } \\
\text { Lewis H. Ziska, Departamento de } \\
\text { Agricultura dos EUA. } \\
\text { Mary H. Hayden, Centro Nacional } \\
\text { de Pesquisas Atmosféricas } \\
\text { Ben Beard, dos Centros de } \\
\text { Controle e Prevenção de } \\
\text { Doenças } \\
\end{array}$ & $\begin{array}{l}\text { Fatores locais são } \\
\text { mais importantes que } \\
\text { o aquecimento global }\end{array}$ & $\begin{array}{l}\text { Incerteza } \\
\text { científica }\end{array}$ \\
\hline 14.02 .16 & $\begin{array}{c}\text { Vírus da zika pode } \\
\text { ter mudado antes } \\
\text { de chegar ao Brasil, } \\
\text { diz virologista }\end{array}$ & $\begin{array}{l}\text { Cotidiano } \\
\text { Entrevista }\end{array}$ & $\begin{array}{l}\text { Leslie Lobel } \\
\text { Universidade Ben Gurion (Israel) }\end{array}$ & $\begin{array}{l}\text { Não se pode excluir } \\
\text { fatores climáticos } \\
\text { na proliferação de } \\
\text { mosquitos }\end{array}$ & Precaução \\
\hline
\end{tabular}

Fonte: Elaboração própria.

De modo geral, evidenciamos que há pouca relação dos problemas de saúde causados pelo mosquito Aedes aegypti e a mudança do clima. No entanto, nosso objetivo é entender quais sentidos são trazidos no discurso veiculado pelo jornal (Quadro 2).

O primeiro sentido é de que há, na ciência e na tecnologia, um aliado para que mapeamentos de florestas sejam realizados. Isso é importante a fim de que seja observado o agravamento da crise climática e, ao mesmo tempo, para dar uma resposta à pressão da sociedade em relação ao papel dos governos em direção às metas do acordo climático. No texto "Plataforma online poderá ajudar a prever epidemias" temos a entrevista com a engenheira do Google, Rebecca Moore, na qual explica o funcionamento de uma ferramenta de mapeamento por satélites, que pode monitorar desmatamento, desastres e evolução de doenças. As questões dirigidas pelo repórter buscam efetivamente traçar um paralelo da tecnologia da informação com a possibilidade de pressão social sobre os governos para a contenção do desmatamento (conforme Sequência Discursiva 1):

SD1: Folha - Como essas informações sobre o planeta colocam pressão sobre os governos? Rebecca - Tor-

nar os dados do planeta acessíveis é muito benéfico para a sociedade. Se há ignorância, não é possível

ter uma discussão pública vibrante e pressionar o governo.

O contexto da entrevista, feita em 16 de maio de 2015, pode ser entendido na medida em que aquele ano foi de fato de preparação para a Conferência de Paris, ocorrida em dezembro, na qual finalmente um novo acordo climático foi acertado entre os países. Perguntada sobre a pressão exercida pelo Imazon ${ }^{3}$, organização não-gover-

3 Fundada em 1990, com sede em Belém (Pará), a ONG é um instituto de pesquisa que atua fortemente na divulgação científica, com dados e mapeamentos sobre questões ambientais relacionadas à região Amazônica. Site da internet: imazon.org.br 
namental que monitora o desmatamento na região amazônica, Rebecca revela que foi a ONG a primeira parceria científica do Google. A questão do desmatamento é, enfim, relacionada à mudança do clima, a partir deste trabalho realizado em conjunto, destacado pelo discurso da fonte:

SD2: Rebecca - Era um momento de negociações do clima e falavam do desmate como uma causa impor-

tante da mudança climática. Acho que podemos, inclusive, ajudar a influenciar essas decisões.

Durante o restante da entrevista, no entanto, o tema não mereceu maior destaque. Dessa forma, o discurso produzido indica uma Formação Discursiva de otimismo tecnológico, na qual o papel da ciência é destacado, porém não se problematiza o quanto as razões da ciência ainda estão distantes da maioria da população e o que exatamente os poderes instituídos fazem a partir do conhecimento científico produzido pela humanidade. $O$ fato de a ciência apontar soluções possíveis é, sem dúvida, um ponto importante, mas os demais atores da sociedade, especialmente do poder econômico e político, caso não atentem para os desafios da mudança do clima, podem desfazer as possibilidades mais otimistas.

No segundo texto, publicado em 15 de agosto de 2015, "Relação entre mais calor e doenças não é clara", temos uma reportagem com a totalidade de fontes científicas. Foram ouvidos três pesquisadores estadunidenses, os quais sustentam a tese de que os fatores locais são mais importantes para a proliferação de doenças do que o aquecimento global.

Vamos nos deter nas sequências discursivas que indicam este sentido geral:

SD3 - Os cientistas concordam que há evidências crescentes de que o aquecimento global afeta nossa saúde, mas dizem que esse é apenas um fator de um conjunto imensamente complexo de forças que influem sobre ela.

SD4 - Os estudos científicos do tema ainda estão em seus primórdios. Nos países em desenvolvimento, os dados sobre insetos, contagem de pólen e doenças muitas vezes são incompletos. Muitos estudos apontam para associações - ou seja, que duas coisas acontecem ao mesmo tempo-, mas não deixam claro se uma coisa é a causa da outra.

SD5 - O calor causou centenas de mortes no Paquistão recentemente. Muitas das vítimas eram adultos mais velhos e pessoas que passavam muito tempo ao ar livre. Cientistas dizem que é praticamente impossível vincular um evento climático específico a mudanças climáticas, mas afirmam com certeza crescente que a temperatura está se elevando.

Os trechos das SDs 3, 4 e 5 indicam que existe uma incerteza de fundamento científico na associação entre doenças e aquecimento global (FD incerteza científica). Contrapõem, na verdade, o conhecimento já dado como consensual pela ciência, especialmente a partir do "IV Relatório do IPCC", publicado em 2007, de que o aquecimento global é inequívoco, no entanto apontam que a mudança do clima pode importar menos que fatores locais. Assim, os cenários sobre os impactos à saúde humana são considerados ainda algo a ser investigado, pois as pesquisas "estão em seus primórdios", ou seja, são iniciais e não poderiam ser consideradas conclusivas. A partir das informações científicas, segundo a matéria, é impossível afirmar a relação entre a mudança do clima e fenômenos específicos, trazendo com isso a ideia de que a ciência tem seus limites na definição de efeitos do aquecimento global.

Em 14 de fevereiro de 2016, no terceiro texto analisado, "Vírus da zika pode ter mudado antes de chegar ao Brasil, diz virologista", temos mais uma entrevista com fonte especializada, um cientista que atua em Israel. O sen- 
tido deste terceiro material é diferenciado, na medida que aponta uma nova interpretação na relação "mudança do clima e saúde". Com o argumento de que os fatores climáticos não são totalmente excluídos na grande proliferação de mosquitos, a Formação Discursiva é da "precaução", evocando-se aqui o próprio princípio da precaução, que alerta a sociedade para que as ações sejam mais refletidas, especialmente quando suas consequências são em parte desconhecidas ou provavelmente prejudiciais à humanidade e ao planeta.

SD6: Folha - Esses ecossistemas podem mudar?

Leslie - Podem. No futuro, o alcance do inseto e do hospedeiro pode mudar, exatamente como o que acon-

teceu com o vírus do Oeste do Nilo, também originalmente de Uganda, que emergiu em Nova York (1999)

e se espalhou no hemisfério norte. Nunca podemos dizer "nunca" em medicina e ciência. 0 aqueci-

mento global pode promover a propagação de insetos e de vírus.

A SD6 é também o último trecho da entrevista publicada pelo jornal. No entanto, por ser contundente em relação à ideia da precaução, determinou a escolha do título dado à matéria, indicando que o vírus zika pode ter sofrido modificações, e, ainda, que possam ter sido provocadas pelo aquecimento global. Podemos compreender como a Formação Discursiva "precaução" traz uma ideia discutida (assim como na reportagem analisada no Texto 2), porém indagando exatamente no ponto em que a incerteza científica merece uma reflexão sobre o futuro das ações da humanidade em relação às consequências, também incertas. Este texto, portanto, mais recente no conjunto analisado, pode ser considerado mais adequado do ponto de vista da comunicação de riscos, pois embora o número de casos de zika no Brasil seja menor quando comparados aos casos de dengue, o alerta para a população deve estar acompanhado de contextualização mais ampla.

\section{Considerações finais}

Os discursos analisados na perspectiva da Comunicação de Riscos e do Jornalismo Ambiental permitem que tracemos algumas considerações sobre como o tema da mudança do clima está apresentado, quando relacionado ao risco de doenças transmissíveis que, no Brasil, em 2015 e 2016, são consideradas epidemias, um problema grave de saúde pública e uma preocupação cotidiana na sociedade.

O primeiro dado que chama atenção é o que encontramos apenas uma reportagem, tarefa que exige mais dos meios de comunicação e dos jornalistas, um investimento que deve ser feito para o esclarecimento da população em relação aos riscos ambientais. Além disso, como as fontes foram somente do campo científico, a abordagem do tema tornou-se monocromática, sem condições de trazer outros elementos sociais e políticos pertinentes. Ora, se um dos fundamentos da comunicação de risco é fazer a intermediação entre os campos sociais, isso é tanto mais eficaz quanto mais fontes possam ser ouvidas sobre os temas em debate. Destacamos também a preferência por fontes estrangeiras. Não que estas não sejam importantes, mas poderiam ser utilizadas pesquisas e especialistas do Brasil, que tanto no tema da mudança do clima quanto da saúde possui centros de referência que poderiam colaborar.

Quando analisados os discursos, encontramos três Formações Discursivas: Otimismo Tecnológico; Incerteza Científica; Precaução. Com estes elementos, podemos concluir que a ciência é abordada de forma diferenciada, no caso da questão ser a mudança do clima e sua relação com as doenças transmitidas pelo aedes, visto que, no otimismo tecnológico, não temos os elementos sociopolíticos enfrentados e discutidos, nem as interações entre 
os campos sociais de maneira geral. No momento em que a incerteza científica é trazida pelo discurso acaba por formular uma não-decisão, tratando de uma incerteza que leva à uma falta de ação efetiva em relação à mudança do clima e, por consequência, em direção à mitigação e adaptação. Por fim, a FD Precaução é aquela que, em alguma medida, consegue formular à sociedade, o impasse civilizatório que vivemos, na medida em que indica que os riscos servem, de forma concreta, mesmo que ainda não comprovados, de alerta para que a sociedade tome novas posturas em relação à crise ambiental.

De modo geral, reforçamos a necessidade de que o jornalismo assuma sua responsabilidade social em relação à comunicação de riscos e indicamos que os pressupostos do Jornalismo Ambiental são potencialmente relevantes para esta tomada de posição. Os leitores, a sociedade em geral, têm o direito de saber quais os riscos da mudança do clima, de que forma o desmatamento afeta a saúde diretamente ou indiretamente, qual a responsabilidade de nossa geração com as seguintes. O jornalismo, para efetivamente promover o debate público eficaz, pelo agendamento midiático "sobre o que pensar" e pelo papel de intermediação entre os poderes, só pode fazê -lo se assumir este compromisso de contextualização, de pluralidade, de questionamento, bases formuladas pelo Jornalismo Ambiental.

\section{Referências}

1. Barcellos, C. et al. (2009). Mudanças climáticas e ambientais e as doenças infecciosas: cenários e incertezas para o Brasil. Epidemiologia e Serviços de Saúde, v. 18, nº. 3, set. Disponível em <http://scielo.iec. pa.gov.br/scielo.php?script=sci_arttext\&pid=S1679-49742009000300011\&lng=pt\&nrm=iso>. Acesso em: 07 fev. 2016. http://dx.doi.org/10.5123/S1679-49742009000300011.

2. Brasil. (2016). Ministério da Saúde. Secretaria de Vigilância em Saúde. Monitoramento dos casos de dengue, febre de chikungunya e febre pelo vírus zika até a Semana Epidemiológica 9, 2016. Boletim Epidemiológico, Brasília, v. 47, n. 16, p. 1-7. Disponível em <http://portalsaude.saude.gov.> Acesso em: 15 abr. 2016.

3. Girardi, I. M. T., Moraes, C. H., Loose, E. B., Neuls, G., Massierer, C., Camana, A., et al. O olhar do jornalismo sobre a Economia Verde: estudo a partir da cobertura da Rio+20 pelos portais G1, UOL e Terra. Líbero (FACASPER), v. 16, p. 71-80.

4. Hannigan, J. A. (1995). A Sociologia ambiental: a formação de uma perspectiva social. Lisboa: Instituto Piaget.

5. Indursky, F. (1998). O sujeito e as feridas narcísicas dos linguistas. In: Gragoatá, Niterói, n. 5, pp. 111-120.

6. Kovach, B., \& Rosenstiel, T. (2004). Os elementos do jornalismo. São Paulo: Geração Editorial.

7. Leff, E. (2009). Ecologia, capital e cultura. Petrópolis, RJ: Vozes.

8. Mendonça, F. (2005). Clima, tropicalidade e saúde: Uma perspectiva a partir da intensificação do aquecimento global, Revista Brasileira de Climatologia, vol. 1, no 1, pp. 100-112.

9. Moraes, C. H. (2015). Entre o clima e a economia: enquadramentos discursivos sobre a Rio+20 nas revistas Veja, Isto É, Época e Carta Capital. Tese de Doutorado (PPGCOM). Porto Alegre: UFRGS.

10. Pêcheux, M. (1990). O discurso: estrutura ou acontecimento. Trad. Eni Orlandi. Campinas/SP: Pontes. 
11. Powell, D., \& Leiss, W. (2005). Um diagnóstico das falhas de Comunicação sobre Riscos. In: Massarani, L., Turney, J., Castro Moreira, I. de. (orgs). Terra Incógnita: a interface entre ciência e público. Rio de Janeiro: FIOCRUZ, pp. 183-201.

12. PNUD. Informe sobre Desarrollo Humano 2007-2008. (2007). La lucha contra el cambio climático: Solidaridad frente a un mundo dividido. New York: Pograma de Naciones Unidas sobre Desarrollo Humano (PNUD).

13. Serra, P. (2009). A mediatização dos riscos: o caso dos riscos ambientais. Disponível em < http://www.bocc. ubi.pt/pag/bocc-serra-mediatizacao.pdf>. Acesso em 28 de julho de 2014.

14. Traquina, N. (2005). Teorias do Jornalismo: Por que as notícias são como são. Florianópolis: Insular. 